\title{
Correlation and Regression Analysis for Yield Traits in Wheat (Triticum aestivum L.) Genotypes
}

\author{
Athar Hussain Bhutto', Asghar Ali Rajpar'1, Shahmir Ali Kalhoro², Amjad Ali3, \\ Fahad Ali Kalhoro', Muneer Ahmed'3, Sajjad Raza', Niaz Ahmed Kalhoro4 \\ ${ }^{1}$ Department of Plant Breeding and Genetics, Sindh Agriculture University, Tando Jam, Pakistan \\ ${ }^{2}$ Faculty of Agriculture, Lasbela University of Agriculture, Water \& Marine Sciences, Uthal, Pakistan \\ ${ }^{3}$ College of Natural Resources and Environment, Northwest A\&F University, Yangling, China \\ ${ }^{4}$ Soil Survey of Pakistan, Devolution Cell, Cabinet Division, Camp Office, Hyderabad, Pakistan \\ Email: shahmirali.agric@luawms.edu.pk
}

Received 18 November 2015; accepted 6 March 2016; published 9 March 2016

Copyright (C) 2016 by authors and Scientific Research Publishing Inc.

This work is licensed under the Creative Commons Attribution International License (CC BY).

http://creativecommons.org/licenses/by/4.0/

c) (i) Open Access

\section{Abstract}

The present research work was carried out at Southern Wheat Research Station, Tandojam during the growing season 2013-14 in order to work out correlation and regression analysis for yield traits in wheat genotypes. The experiment was laid out in a Randomized Complete Block Design with three replications. Eight bread wheat genotypes such as Mehran, Sarsabz, TJ-83, SKD-1, Inqlab, A. Sattar, Sehar and Sassui were used to examine correlation and regression. Seven traits, viz;; plant height, tillers plant ${ }^{-1}$, spike length, spikelet's spike ${ }^{-1}$, grains spike ${ }^{-1}$, seed index and grain

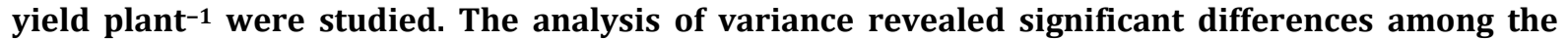
genotypes for plant height, tillers plant ${ }^{-1}$, spike length, spikelet's spike ${ }^{-1}$, grains spike ${ }^{-1}$, seed index and grain yield plant $^{-1}$. Based on mean performance, variety Sarsabz gave maximum plant height (95.46), produced maximum tillers plant $^{-1}(4.40)$, gave more grain spike ${ }^{-1}(63.13)$, TJ-83 gave highest seed index (47.260), and was next ranker in spike length ${ }^{-1}(12.07)$, spikelet's spike-1 (19.13), grains spike ${ }^{-1}(59.86)$, and grain yield plant ${ }^{-1}(9.86)$ among the genotypes. The phenotypic correlations revealed that tillers plant ${ }^{-1}$ and grains spike ${ }^{-1}$ were highly positively associated; hence these yield components can be used as reliable selection criteria to improve grain yield in wheat. Thus estimation of correlation and regression analysis among yield and yield components may provide effective selection criteria to improve wheat grain yield. The results from correlation and regression of plant height indicated significantly positive association with spikelet's spike ${ }^{-1}$, tillers plant ${ }^{-1}$ and grains spike ${ }^{-1}$ which revealed that increase in plant height will cause corresponding increase in associated traits. 


\section{Keywords}

\section{Wheat, Grain, Yield, Genotype, Analysis}

\section{Introduction}

Major cultivated species of wheat is Triticum aestivum, which is a hexaploid $(2 n=6 x=42)$. Pakistan ranks among the top ten leading wheat producing countries of the world. Wheat (Triticum aestivum L.) is used as a staple food of the major civilizations since old times. It is most extensively grown crop among cereals in the world, engaging $17 \%$ of crop acreage from world over, giving food to about $40 \%$ of world population and supplying $20 \%$ of the total food calories and protein in human diet. In Pakistan, the production of 24.231 million tons was achieved during 2012-13 showing 3.20 percent increase over the preceding year, whereas the yield was $2787 \mathrm{~kg} \cdot \mathrm{ha}^{-1}$, showing 2.7 percent increase over the last years yield $\mathrm{ha}^{-1}$. Thus, it indicated a positive trend in the area, grain production and yield per hectare, and this was mainly associated with the timely sowing of wheat and favorable climatic factors [1].

Wheat grain yield varies widely as a consequence of its interaction with a variety of environmental factors since it is a complex quantitative genetic parameter and is the result of numerous contributing factors affecting grain yield directly or indirectly. Wheat grain production can be improved through the development of productive varieties which better adjust in diverse agro-climatic conditions and also resist all types of biotic stresses. Selection and improvement in respect to grain yield can only be efficient if adequate genetic variability exits in the breeding materials [2].

Being staple food grain, it contributes 42 percent of total calories required per capita per day; the wheat straw is also important as fodder. Consequently, it occupies a central position in agricultural economy and policies. Pakistan has been a net importer of wheat for the past several decades. It imports about two million tons of wheat at cost of eight billion rupees [3].

Whole grain wheat is a good source of protein and dietary fiber. It has higher protein content, about $14 \%$, than any other whole grain. The protein in wheat contains all eight essential amino acids and is deficient only in lysine, which can be added back into a diet with beans or meats. Most of the dietary fiber in wheat is insoluble, which improves bowel health; some studies have shown that it may help to reduce the risk of colorectal cancer. Wheat grain is also a good source of many important vitamins and minerals, such as vitamin B, vitamin E, thiamin, niacin, iron, riboflavin, magnesium, selenium, potassium, phosphorus, and calcium. Breeders all over the world have been utilizing the available genetic resources to modify the varieties to meet requirements of ever increasing population. In crop breeding program the principle objective is to increase yield and improve other desirable quantitative characters. New wheat varieties may originate through introduction, selection, hybridization, mutation and genetic engineering. It is well known fact that quantitative characters, depending on the nature of gene action, are differently influenced by environmental variation. Moreover, the extents of heritability of quantitative traits are negatively correlated with environment. Heritability of traits indicated greater influence of environmental factors over genetic makeup of traits [4].

Vavilov [5] emphasized that correlation study is an important phase of breeding which was started in the last decades of $19^{\text {th }}$ century and the beginning of $20^{\text {th }}$ century in order to simplify breeders work and for easy handling of material. Such investigations have to be carried out in various types of crop plants. Vavilov pleaded pleiotropic gene effects being major causes of genetic correlation as a number of characters are conditioned by the effect of single gene.

The association between any two variables is known as simple correlation; it can be estimated from both un-replicated as well as replicated data. Simple correlation is of three types: 1) Phenotypic, 2) Genotypic and 3) Environmental. Phenotypic correlation is the observable correlation between two variables; it includes both genotypic and environmental effects. Genotypic correlation, on the other hand, is the inherent association between two variables; it may be due to pleiotropic action of genes, linkages or more likely both. Similarly, environmental correlation is entirely due to environmental effects [6].

Selection for grain yield can only be effective if desired genetic variability is present in the genetic stock. Genotypic and phenotypic correlations are important in determining the degree to which various yield contri- 
buting characters are associated. Several researchers have reported their findings regarding the correlation studies. [7]-[12] reported positive correlation of grain yield with a number of grains per spike, plant height and 1000 grain weight. However [12] [13] conducted such studies and concluded that yield components like tillers per plant, grains per spike and 1000 grain weight are main contributors to grain yield in wheat. Keeping in view the present situation, this research is designed to meet the objectives to estimate the correlation between yield components and seed yield in wheat and to work out regression of grain yield on its components.

\section{Materials and Methods}

A study was conducted during Rabi season 2013-14 at Southern Wheat Agriculture Research station, Tandojam, to evaluate the correlation and regression analysis of yield traits of wheat (Triticum aestivum L.) genotypes.

The experimental material was sown in randomized complete block design with three replications. The trial consisted of four rows of 11 feet length for each genotype per replication. The sowing was done by dibbling, keeping 20 centimeters space between plants and $30 \mathrm{~cm}$ between rows. Ten plants were randomly selected and tagged from each replication. After collecting necessary data under field conditions further observations were recorded at laboratory.

The experimental material consisted of following verities:

1) $V_{1}$ : Mehran

2) $V_{2}:$ Sarsabz

3) $V_{3}: T J-83$

4) $V_{4}:$ SKD-1

5) $V_{5}:$ Inqlab

6) $\mathrm{V}_{6}$ : Abdul Sattar

7) $V_{7}$ : Sehar

8) $V_{8}$ : Sassui

\section{Plant height}

At the time of maturity, the height of each selected plant was measured in centimeters from the surface of soil to the tip of ear-head excluding awns.

\section{Number of Tillers plant ${ }^{-1}$}

The numbers of fertile tillers produced by each selected plant were counted at the time of maturity and replication wise data were recorded.

\section{Spike length}

Length of the spike of main tiller was measured in centimeters from the base of spike to the upper most spikelet excluding awns.

\section{Number of spikelet's spike ${ }^{-1}$}

The numbers of spikelets in the primary tiller of each selected plant were counted and the data were recorded as spikelet's spike ${ }^{-1}$.

\section{Number of grains spike ${ }^{-1}$}

The main spike of primary tiller of each selected plant was threshed separately, numbers of grains were counted and replication wise data were recorded.

\section{Seed Index (1000 grain weight)}

1000 grains were randomly taken from each selected plant and were weighed in grams on electric balance in laboratory.

\section{Grain yield plant $^{-1}$}

After harvesting, each selected plant was threshed separately with single plant wheat thresher and cleaned in the laboratory. The grains were weighed on electric balance and yield plant ${ }^{-1}$ was recorded in grams.

The collected data were analyzed through New Student Statistics Software SXW Package. Correlation coefficients were worked out between 21 character combinations as shown below:

1. Plant height and number of fertile tillers plant ${ }^{-1}$.

2. Plant height and spike length.

3. Plant height and number of spikelet spike ${ }^{-1}$.

4. Plant height and number of grains spike ${ }^{-1}$.

5. Plant height and grain yield plant ${ }^{-1}$. 
6. Plant height and Seed index.

7. Number of fertile tillers plant ${ }^{-1}$ and spike length.

8. Number of fertile tillers plant ${ }^{-1}$ and number of spikelet's per spike.

9. Number of fertile tillers plant ${ }^{-1}$ and number of grains spike ${ }^{-1}$.

10. Number of fertile tillers plant ${ }^{-1}$ and grain yield plant ${ }^{-1}$.

11. Number of fertile tillers plant ${ }^{-1}$ and seed index.

12. Spike length and number of spikelet's spike ${ }^{-1}$.

13. Spike length and number of grains spike ${ }^{-1}$.

14. Spike length and grain yield plant ${ }^{-1}$.

15. Spike length and seed index.

16. Number of spikelet's per spike and number of grains spike ${ }^{-1}$.

17. Number of spikelet's per spike and number of Seed index.

18. Number of spikelet's spike ${ }^{-1}$ and grain yield per plant.

19. Number of grains spike ${ }^{-1}$ and seed index.

20. Number of grains spike ${ }^{-1}$ and grain yield per plant.

21. Seed index and grain yield plant ${ }^{-1}$.

Simple correlation (r) and regression coefficients (b) were calculated by Snedecor and Cochran (1980) [14] methods.

\section{Results and Discussion}

The present research was conducted to find out the correlation and regression of different traits viz. Plant height $(\mathrm{cm})$, tillers plant ${ }^{-1}$, spike length $(\mathrm{cm})$, spikelet's spike ${ }^{1}$, grains spike ${ }^{-1}$, seed index (g) and grain yield plant ${ }^{-1}$ (g). Eight genotypes of wheat (Triticum aestivum L.) were used.

The genotypes were evaluated for their analysis of variance (ANOVA), mean performance, correlation and regression. The data regarding analysis of variance (ANOVA) of eight genotypes for seven quantitative traits are presented in Table 1. The mean performance of eight genotypes for different traits studied is summarized in Table 2. The correlation and regression analysis for various traits are depicted in Table 3.

\section{Analysis of variance (ANOVA)}

The analysis of variance showed that genotypes were significantly different $(P \leq 0.01)$ for all the traits viz. plant height $(\mathrm{cm})$, spike length $(\mathrm{cm})$, spikelet's spike ${ }^{1}$, grains spike ${ }^{-1}$, seed index grain weight (g) and grain yield plant $^{-1}$ (g) but tillers plant ${ }^{-1}$ were non-significant. The results revealed significant differences in the mean performance of varieties. These results further suggested that the entire data can be processed for analysis to estimate correlation and regression. The results in respect to mean performance, correlation and regression are presented here under.

\section{Mean performance}

The data regarding mean performance of eight parental lines evaluated for seven quantitative traits in wheat are summarized in Table 2. Most of the genotypes gave higher mean values for all the traits studied. However,

Table 1. Mean squares from analysis of variance (ANOVA) for yield traits in wheat (Triticum aestivum L.).

\begin{tabular}{|c|c|c|c|}
\hline \multirow{2}{*}{ Traits } & \multicolumn{3}{|c|}{ Mean squares } \\
\hline & Replication D.F. = 2 & Varieties D.F. $=7$ & Error D.F. $=14$ \\
\hline Plant height & 6.66 & $69.19^{* *}$ & 6.29 \\
\hline Tillers plant $^{-1}$ & 0.18 & $0.31 \mathrm{NS}$ & 0.20 \\
\hline Spike length & 0.34 & $2.80^{* *}$ & 0.2 \\
\hline Spikelet's spike ${ }^{-1}$ & 1.32 & $10.16^{* *}$ & 0.62 \\
\hline Grains spike $^{-1}$ & 1.82 & $214.56^{* *}$ & 2.95 \\
\hline Seed index (1000 grain wt) & 549.68 & $2197.99^{* *}$ & 280.74 \\
\hline Grain yield plant ${ }^{-1}$ & 0.38 & $9.04^{* *}$ & 0.45 \\
\hline
\end{tabular}

\footnotetext{
** = Significant at $1 \%$ probability level; NS = Significant at $1 \%$ probability level.
} 
Table 2. Mean performance for yield traits in eight wheat genotypes.

\begin{tabular}{|c|c|c|c|c|c|c|c|c|c|}
\hline \multirow{2}{*}{ Characters } & \multicolumn{9}{|c|}{ Varieties } \\
\hline & Mehran & Sarsabz & TJ-83 & SKD-1 & Inqlab & A.Sattar & Sehar & Sassui & L.S.D. (5\%) \\
\hline Plant height (cm) & 93.80 & 95.46 & 89.40 & 84.53 & 81.46 & 85.53 & 91.40 & 87.20 & 4.39 \\
\hline Tillers plant ${ }^{-1}$ & 3.86 & 4.40 & 4.40 & 3.60 & 4.00 & 3.60 & 4.26 & 3.93 & 0.78 \\
\hline Spike length (cm) & 9.94 & 11.70 & 12.07 & 11.00 & 10.38 & 10.96 & 11.00 & 12.98 & 0.83 \\
\hline Spikelet spike $^{-1}$ & 17.80 & 18.73 & 19.13 & 17.26 & 14.20 & 16.06 & 18.73 & 19.80 & 1.38 \\
\hline Grains spike $^{-1}$ & 40.93 & 63.13 & 59.86 & 45.33 & 42.73 & 46.53 & 57.53 & 54.33 & 3.00 \\
\hline $\begin{array}{c}\text { Seed index } \\
\text { (1000 grain weight) (g) }\end{array}$ & 41.483 & 40.507 & 47.260 & 46.680 & 46.407 & 46.693 & 43.360 & 42.427 & 2.934 \\
\hline Grain yield plant ${ }^{-1}(\mathrm{~g})$ & 6.20 & 8.00 & 9.86 & 6.80 & 5.93 & 6.80 & 10.06 & 8.60 & 1.18 \\
\hline
\end{tabular}

Table 3. Correlation (r), regression coefficients (b) and coefficient of determination $\left(r^{2}\right)$ of traits in wheat genotypes.

\begin{tabular}{|c|c|c|c|}
\hline Character Association & Correlation Coefficient (r) & Regression Coefficient (b) & Coefficient of Determination $\left(r^{2}\right)$ \\
\hline 1. Plant height vs. Tillers per plant & $0.583^{* *}$ & 8.574 & 0.339 \\
\hline 2. Plant height vs. Spike length & -0.044 NS & 0.216 & 0.002 \\
\hline 3. Plant height vs. Spikelet's spike ${ }^{-1}$ & $-0.648^{* *}$ & 1.707 & 0.42 \\
\hline 4. Plant height vs. Grains spike & $0.519^{*}$ & 0.295 & 0.26 \\
\hline 5. Plant height vs. Grain yield plant ${ }^{-1}$ & $-0.775^{* *}$ & -0.138 & 0.60 \\
\hline 6. Plant height vs. Seed index & 0.422 NS & 1.158 & 0.17 \\
\hline 7. Tillers per plant vs. Spike length & $0.269 \mathrm{NS}$ & 0.099 & 0.07 \\
\hline 8. Tillers per plant vs. Spikelet's spike ${ }^{-1}$ & $0.440^{*}$ & 0.079 & 0.19 \\
\hline 9. Tillers per plant vs. Grains spike & $0.778^{* *}$ & 0.033 & 0.60 \\
\hline 10. Tillers per plant vs. Grain yield plant & $-0.332 \mathrm{NS}$ & -0.004 & 0.11 \\
\hline 11. Tillers per plant vs. Seed index & $0.704^{* *}$ & 0.131 & 0.49 \\
\hline 12. Spike length vs. Spikelet's spike ${ }^{-1}$ & $0.671^{* *}$ & 0.366 & 0.45 \\
\hline 13. Spike length vs. Grains spike & 0.695 NS & 0.088 & 0.48 \\
\hline 14. Spike length vs. Grain yield plant & $-0.076 \mathrm{NS}$ & -0.003 & 0.05 \\
\hline 15. Spike length vs. Seed index & $0.147 \mathrm{NS}$ & 0.082 & 0.02 \\
\hline 16. Spikelet’s spike vs. Grains spike & $0.697^{* *}$ & 0.155 & 0.48 \\
\hline 17. Spikelet's spike vs. Seed index & $-0.490^{*}$ & -0.033 & 0.24 \\
\hline 18. Spikelet's spike vs. Grain yield plant & 0.417 NS & 0.434 & 0.17 \\
\hline 19. Grain spike vs. Seed index & $0.282 \mathrm{NS}$ & -0.088 & 0.07 \\
\hline 20. Grain spike vs. Grain yield plant & $0.690^{* *}$ & 3.331 & 0.47 \\
\hline 21. Seed index vs. Grain yield plant & 0.099 NS & 1.534 & 0.09 \\
\hline
\end{tabular}

\footnotetext{
"Significant at 0.01 level of probability, "Significant at 0.05 level of probability, “NS Non significant”.
}

genotype SARSABZ gave maximum plant height (95.46), produced maximum tillers plant ${ }^{-1}$ (4.40), gave more grains spike $^{-1}$ (63.13), but gave lowest seed index (40.07). While the genotype TJ-83 also produced maximum tillers plant ${ }^{-1}$ (4.40), and highest seed index (47.26), and was next ranker in spike length (12.07), spikelet's 
spike $^{-1}$ (19.13), grains spike ${ }^{-1}$ (59.86), and grain yield plant ${ }^{-1}$ (9.86) among the genotypes. The genotype Sassui gave longer spike length (12.98), gave maximum spikelet's spike ${ }^{-1}$ (19.80), Mehran ranked next maximum in plant height (93.80), and ranked minimum in spike length ${ }^{-1}$ (9.94), grains spike ${ }^{-1}$ (40.93), Sehar gave maximum grain yield plant ${ }^{-1}$ (10.06), ranked next maximum in tillers plant ${ }^{-1}$ (4.26). Genotype SKD-1 produced minimum tillers plant ${ }^{-1}(3.60)$, A. Sattar also produced minimum tillers plant ${ }^{-1}$ (3.60), and gave next maximum seed index grain yield (46.93). The genotype Inqlab gave lowest mean performance for many traits.

Correlation (r) and regression coefficient (b)

Correlation and regression analysis of wheat yield and its contributing components are very important in determining suitable selection criteria for the improvement of higher wheat yield. The data regarding simple correlation coefficient (r), coefficient of determination $\left(\mathrm{r}^{2}\right)$ and regression coefficient (b) of wheat yield, its components and various traits of eight varieties is presented in Table 3.

Plant height v/s No. of tillers plant ${ }^{-1}$

Plant height showed positive and highly significant correlation with number of tillers $\left(r=0.583^{* *}\right)$. This relationship reveals that if plant height increases the numbers of tillers are also increased.

Plant height v/s spike length

Association between plant height and spike length revealed negative and non-significant correlation $(\mathrm{r}=$ $-0.044^{\mathrm{NS}}$ ), referring as plant height has no effect on spike length.

Plant height v/s spikelet's spike ${ }^{-1}$

The phenotypic correlation between plant height and spikelet's spike ${ }^{-1}$ showed negative and highly significant relationship $\left(\mathrm{r}=-0.648^{* *}\right)$. This shows that the character spikelet's spike ${ }^{-1}$ is dependent on plant height ${ }^{-1}$, as the spikelet's spike ${ }^{-1}$ would decrease with the increasing plant height.

Plant height $\mathrm{v} / \mathrm{s}_{\text {grains spike }}{ }^{-1}$

Interrelationship between these two traits showed positive and significant correlation $\left(r=0.519^{*}\right)$, revealing that with the increase in plant height, grains per plant will also increase proportionately.

Plant height v/s seed index

Plant height and seed index interrelationship revealed negative and highly significant correlation $(\mathrm{r}=$ $-0.775^{* * *}$ ), which influenced that seed index is dependent on the character plant height.

Plant height v/s grain yield

Correlation between plant height and yield per plant was positive and non-significant $\left(r=0.422^{\mathrm{NS}}\right)$. This emphasized that as plant height increases yield also increases.

\section{Number of tillers plant ${ }^{-1} \mathrm{v} / \mathrm{s}$ spike length}

Interrelation between number of tillers per plant with spike length showed positive and non-significant correlation $\left(r=0.269^{\mathrm{NS}}\right)$. It means, as the tillers increase, the spike length will also increase simultaneously.

Number of tillers plant ${ }^{-1} \mathrm{v} / \mathrm{s}$ spikelet's spike $\mathrm{e}^{-1}$

The data depicted in Table 3 reveals that correlation for number of tillers per plant with spikelet's per spike was positive and significant $\left(\mathrm{r}=0.440^{*}\right)$. This shows that both the characters are independent.

Number of tillers plant ${ }^{-1} \mathrm{v} / \mathbf{s}_{\text {grains }}$ spike $^{-1}$

The association of these two traits showed positive and highly significant correlation $\left(r=0.778^{* *}\right)$. As the tillers increase the grains per spike will reduce in number but not to the significant level.

\section{Number of tillers plant ${ }^{-1} \mathrm{v} / \mathrm{s}$ seed index}

Number of tillers per plant had negative and non-significant correlation with seed index $\left(\mathrm{r}=-0.332^{\mathrm{NS}}\right)$, showing that as tillers increased, seed index reduced ultimately.

\section{Number of tillers plant ${ }^{-1} \mathrm{v} / \mathrm{s}$ grain yield plant ${ }^{-1}$}

Number of tillers showed positive and highly significant correlation with yield per plant $\left(\mathrm{r}=0.704^{* *}\right)$. This shows that any increase in number of tillers will result in proportionate increase in yield per plant.

Spike length $\mathrm{v} / \mathrm{s}$ spikelet's spike ${ }^{-1}$

Association between spike length and spikelet's per spike is given in Table 3. The association revealed positive and highly significant correlation between both characters $\left(r=0.671^{* *}\right)$. It shows that with every unit increase in spike length, yield will also increase proportionately.

Spike length $\mathrm{v} / \mathrm{s}_{\text {grains }}$ spike $^{-1}$

These two traits were positive and non-significantly correlated to each other $\left(r=0.695^{\mathrm{NS}}\right)$, showing that as spike length increases the grains per spike will increase ultimately.

Spike length $\mathrm{v} / \mathrm{s}$ seed index 
Correlation between spike length and seed index (Table 3) was positive and non-significant $\left(\mathrm{r}=-0.076^{\mathrm{NS}}\right.$ ).

This association reveals that as spike length increases seed index will also decrease simultaneously.

Spike length $\mathrm{v} / \mathrm{s}$ grain yield plant $^{-1}$

The Table 3 indicates that Spike length was positive and non-significant correlated with yield per plant $(\mathrm{r}=$ $0.147^{\mathrm{NS}}$ ).

\section{Spikelet's spike $^{-1} \mathrm{v} /$ s grains spike $^{-1}$}

The spikelet's per spike and grain per spike revealed positive and highly significant correlation with each other $\left(r=0.697^{* * *}\right)$ emphasizing that as the spikelet's per spike are increased, the grains per spike will also increase.

\section{Spikelet's spike ${ }^{-1} \mathrm{v} / \mathrm{s}$ seed index}

Spikelet's per spike showed positive and significant correlation with seed index $\left(\mathrm{r}=-0.490^{*}\right)$ showing that as spikelet's per spike would increase the seed index will also decrease.

Spikelet's spike ${ }^{-1} \mathrm{v} / \mathrm{s}$ grain yield plant ${ }^{-1}$

Association between spikelet's per spike with yield per plant was positive and non-significant correlation with each other $\left(r=0.417^{\mathrm{NS}}\right)$.

Grain spike $^{-1} \mathrm{v} / \mathrm{s}$ seed index

Grain per spike had positive and non-significant correlation with seed index $\left(r=0.282^{\mathrm{NS}}\right)$. This association shows that as grains per spike increased the seed index will also increase.

Grain spike $^{-1} \mathrm{v} / \mathrm{s}$ grain yield plant ${ }^{-1}$

Interrelationship between grain per spike and yield per plant had positive and highly significant correlation ( $\mathrm{r}$ $=0.690^{* *}$ ).

Seed index v/s grain yield plant ${ }^{-1}$

The data revealed that seed index relationship with yield was positive and non-significant correlated with each other $\left(r=0.099^{\mathrm{NS}}\right)$.

The genotypes were evaluated for their analysis of variance (ANOVA), mean performance, correlation and regression. The data regarding analysis of variance (ANOVA) of eight genotypes for seven quantitative traits are presented in Table 1. The mean performance of eight genotypes is summarized in Table 2 for different traits studied. The correlation and regression effects for various traits are depicted in Table 3.

The analysis of variance for genotypes was significantly different $(P \leq 0.01)$ for all the traits viz. Plant height $(\mathrm{cm})$, tillers plant ${ }^{-1}$, spike length $(\mathrm{cm})$, spikelet's spik ${ }^{1}$, grains spike ${ }^{-1}$, seed index grain weight $(\mathrm{g})$ and grain yield plant ${ }^{-1}$ (g). These results revealed significant differences in the mean performance of varieties. These results further suggested that the entire data can be processed for analysis to estimate correlation and regression. The results in respect to mean performance, correlation and regression are presented here under.

The data regarding mean performance of eight parental lines evaluated for seven quantitative traits in wheat are summarized in Table 2. Most of the genotypes gave higher mean values for all the traits studied. However, genotype Sarsabz gave maximum plant height (95.46), produced maximum tillers plant ${ }^{-1}$ (4.40), gave more grain spike ${ }^{-1}$ (63.13), but gave lowest seed index grain weight (g) (40.507). While the genotype TJ-83 also produced maximum tillers plant $^{-1}$ (4.40), and highest seed index grain weight (47.260), and was next ranker in spike length (12.07), spikelet's spike ${ }^{-1}$ (19.13), grain spike ${ }^{-1}$ (59.86), and grain yield plant ${ }^{-1}$ (9.86) among the genotypes. The genotype Sassui gave longer spike length (12.98), gave maximum spikelet's spike ${ }^{-1}(19.80)$, Mehran ranked next maximum in plant height ${ }^{-1}$ (93.80), and ranked minimum in spike length ${ }^{-1}$ (9.94), grain spike $^{-1}$ (40.93), Sehar gave maximum grain yield plant ${ }^{-1}$ (10.06), ranked next maximum tillers plant ${ }^{-1}$ (4.26). Genotype SKD-1 produced minimum tillers plant ${ }^{-1}$ (3.60), A. Sattar also produced minimum tillers plant $^{-1}$ (3.60), and gave next maximum seed index grain yield (g) (46.693). The genotype Inqlab gave lowest mean performance for many traits. Similar findings were reported by Biju and Malik (2006) [15], Safeer-ul-Hassan et al. (2004) [16], Singh and Singh (2001) [17]. They reported that seed index had the highest positive correlation with grain yield $(\mathrm{r}=0.9371)$.

Plant height showed positive correlation with number of tillers but was positive and highly significant $(\mathrm{r}=$ 0.583). This relationship reveals that if plant height increases the numbers of tillers are also increased. Association between plant height and spike length revealed negative and non-significant correlation $(r=-0.044)$, referring as plant height has no effect on spike length. The phenotypic correlation between plant height and spikelet's per spike showed negative and highly significant relationship $(\mathrm{r}=-0.648)$. This shows that the character spikelet's per spike are dependent on plant height, as the spikelets per spike would increase with the plant height. 
Plant height and grain per spike Interrelationship between these two traits showed positive and significant correlation $(r=0.519)$, revealing that the grains per spike is dependent the character plant height. Plant height and seed index interrelationship revealed negative and highly significant correlation $(r=-0.775)$, which influenced that seed index is dependent on the character plant height. Correlation between plant height and yield per plant was positive and non-significant $(r=0.422)$. This emphasized that as plant height increases yield also increases. Interrelation between number of tillers per plant with spike length showed positive and non-significant correlation $(r=0.269)$. It means, as the tillers increase, the spike length will reduce simultaneously. The data depicted in Table 3 reveals that correlation for number of tillers per plant with spikelet's per spike was positive and significant $(r=0.440)$. This shows that both the characters are independent. The association of these two traits showed positive and highly significant correlation $(r=0.778)$. As the tillers increase the grains per spike will reduce in number but not to the significant level. Number of tillers per plant had negative and non-significant correlation with seed index $(\mathrm{r}=-0.332)$, showing that as tillers increased, seed index reduced ultimately. Number of tillers showed positive and highly significant correlation with yield per plant $(r=0.704)$. This shows that any increase in number of tillers will result in proportionate increase in yield per plant. Association between spike length and spikelet's per spike is given in Table 3 . The association revealed positive and highly significant correlation between both characters $(\mathrm{r}=0.671)$. It shows that with every unit increase in spike length, yield will also increase proportionately. These two traits were positive and non-significantly correlated to each other $(\mathrm{r}=$ 0.695) showing that as spike length increases the grains per spike will increase ultimately. Correlation between spike length and seed index (Table 3$)$ was negative and non-significant. $(r=-0.076)$. This association reveals that as spike length has no effect on seed index. The Table 3 indicates that Spike length was positive and nonsignificantly correlated with yield per plant $(r=0.147)$. The spikelet's per spike and grains per spike revealed positive and significant correlation with each other $(r=0.697)$ emphasizing that as the spikelet's per spike are increased, the grains per spike will increase also. Spikelet's per spike showed negative and significant correlation with seed index $(r=-0.490)$ showing that as spikelet's per spike would increase the seed index will also increase. Association between spikelet's per spike with yield per plant was positive and revealed non-significant correlation with each other $(r=0.417)$. Grains per spike had positive and non-significant correlation with seed index $(r=0.282)$. This association shows that as grains per spike increased the seed index will also increase. Interrelationship between grain per spike and yield per plant had positive and highly significant correlation $(r=$ 0.690). The data revealed that seed index relationship with grain yield plant was positive and non-significantly correlated with each other $(\mathrm{r}=0.99)$. Our findings are in conformity with Fida et al. (2006) [18], Kumar et al. (2005) [19], Kumar et al. (2002) [20], who reported that grain yield per plant was significantly and positively correlated with number of tillers per plant and seed index. In the view of above results, it can be suggested that number of tiller per plant, plant height, spike length and seed index are major contributors for increasing the grain yield per plant and selection could be more effective for these traits .

\section{Conclusion}

The analysis of variance for genotypes was significantly different $(P \leq 0.01)$ for all the traits viz. plant height $(\mathrm{cm})$, spike length $(\mathrm{cm})$, spikelet's spik ${ }^{1}$, grains spike ${ }^{-1}$, seed index grain weight (g) and grain yield plant ${ }^{-1}(\mathrm{~g})$. These results revealed significant differences in the mean performance of genotypes. Based on mean performance, variety Sarsabz gave maximum plant height (95.46), produced maximum tillers plant ${ }^{-1}$ (4.40), gave more grain spike ${ }^{-1}$ (63.13), TJ-83 highest seed index grain weight (47.260), and was next ranker in spike length ${ }^{-1}$ (12.07), spikelet's spike ${ }^{-1}(19.13)$, grain spike ${ }^{-1}$ (59.86), and grain yield plant $^{-1}$ (9.86) among the genotypes. The phenotypic correlations revealed that tillers plant ${ }^{-1}$ and grain per spike were highly positively associated and coefficient determination $\left(\mathrm{r}^{2}\right)$ with grain yield plant ${ }^{-1}$; hence these yield components can be used as reliable selection criteria to improve grain yield in wheat. Thus estimation of correlation and regression analysis among yield and yield components may provide effective selection criteria to improve wheat grain yield. The results from correlation and regression of plant height indicated that significantly positive association with spikelet per spike $^{-1}$, tillers per plant, grain per spike, grain yield revealed that increase in plant height will cause corresponding increase in associated traits.

\section{References}

[1] GOP (2013) Area and Production of Major Kharif and Rabi Crops. Economic Survey of Pakistan (2012-13), Ministry 
of Food and Agriculture, Federal Bureau Statistics, Government of Pakistan, Islamabad, 22.

[2] Ali, Y., Atta, M.B., Akhter, J., Monneveux, P. and Lateef, Z. (2008) Genetic Variability, Association and Diversity Studies in Wheat (Triticum aestivum L.) Germplasm. Pakistan Journal of Botany, 40, 2087-2097.

[3] Mahmood, M.A. and Sheikh, A.D. (2006) Technologies for Increasing Wheat Crop. http://www.Pakissan.com

[4] Ansari, K.A. and Ansari, B.A. (1996) Heritability Estimates of Yield and Yield Related Components in Bread Wheat (Triticum aestivum L.). Sarhad Journal of Agriculture, 13, 601-606.

[5] Vavilov, N.I. (1951) The Origin, Variation, Immunity and Breeding of Cultivated Plants (Translated by S. K. Chestitee). Chronica Botonica, 13, 1-366.

[6] Singh, B.D. (1993) Plant Breeding. 5th Edition, Kalyani Publishers, Rajender Nagar, Ludhiana, India, 110-111.

[7] Sandhu, B.S. and Mangat, N.S. (1985) Interrelationships in Some Quantitative Traits in Wheat. Indian Journal of Agricultural Research, 19, 98-102.

[8] Eunus, M., Sarker, D.C., Khan, Z.A. and Sarker, A.U. (1986) Interrelationships among Some Quantitative Characters of Wheat. Bangladesh Journal of Agricultural Research, 11, 91-94.

[9] Chowdhry, M.A., Alam, K. and Khaliq, I. (1991) Harvest Index in Bread Wheat. Pakistan Journal of Agricultural Sciences, 28, 207-210.

[10] Belay, G., Tesemma, T. and Mitiku, D. (1993) Variability and Correlation Studies in Durum Wheat in Alem-Tena, Ethiopia. Rachis, 12, 38-41.

[11] Aycecik, M. and Yildirim, T. (2006) Path Coefficient Analysis of Yield and Yield Components in Bread Wheat (Triticum aestivum L.) Genotypes. Pakistan Journal of Botany, 38, 417-424.

[12] Gupta, A.K., Mittal, R.K. and Ziauddin, A. (1999) Association and Factor Analysis in Spring Wheat. Annals of Agricultural Research, 20, 481-485.

[13] Chowdhry, M.A., Ali, M., Subhani, G.M. and Khaliq, I. (2000) Path Coefficient Analysis for Water Use Efficiency, Evapo-Transpiration Efficiency, Transpiration Efficiency and Some Yield Related Traits in Wheat. Pakistan Journal of Biological Sciences, 3, 313-317. http://dx.doi.org/10.3923/pjbs.2000.313.317

[14] Al-Rashidi, G.A. (2004) The Effect of N and P Fertilizers Application on the Growth and Yield of Wheat Crop var. Kalyansona. University of Aden Journal of Natural and Applied Sciences, 8, $19-24$.

[15] Biju, S. and Malik, S.K. (2006) Association Analysis in Wheat. International Journal of Agriculture Sciences, 2, 427428

[16] Safeer-ul-Hassan, M., Munir, M., Mujahid, M.Y., Kisana, N.S., Akram, Z. and Nazeer, A.W. (2004) Genetic Analysis of Some Biometric Characters in Bread Wheat (Triticum aestivum L). Journal of Biological Sciences, 4, 480-485.

[17] Singh, S.B. and Singh, T.B. (2001) Correlation and Path Analysis in Common Wheat (Triticum aestivum L.) under Light Texture Soil. Research on Crops, 2, 99-101.

[18] Fida, M., Jadoon, S.A., Rashid, S.M. and Shaheen, S. (2006) Heritability Estimates for Coleoptile Length and Other Traits in Bread Wheat. Sarhad Journal of Agriculture, 22, 405-408.

[19] Kumar, S., Mittal, R.K., Gupta, D. and Katna, G. (2005) Correlation among Some Morpho-Physiological Characters Associated with Drought Tolerance in Wheat. Annals of Agri Bio Research, 10, 129-134.

[20] Kumar, R., Ram, B. and Singh, S.P. (2002) Studies on Yield and Its Component Traits in Bread Wheat (Triticum aestivum L.). New Botanist, 29, 175-180. 